L CAZADOR HUMANO. UNA VISIÓN ANTROPOLÓGICA, SOCIOLÓGICA Y ECOLÓGICA / THE HUMAN HUNTER. AN ANTHROPOLOGICAL, SOCIOLOGICAL AND ECOLOGICAL APPROACH

\section{LA CAZA VS. LA CRÍA DE UNGULADOS CINEGÉTICOS: LA PRODUCCIÓN DE NATURALEZA COMO RESPUESTA A LAS EXIGENCIAS DE LA SOCIEDAD OCCIDENTAL DEL SIGLO XXI}

\author{
Pedro Corell Alcantarilla \\ Asociación Española de Criadores de Ungulados Silvestres \\ ORCID iD: http://orcid.org/0000-0002-6263-0054 \\ pedro@losclaros.es
}

Cómo citar este artículo/Citation: Corell Alcantarilla, P. (2017). La caza vs. la cría de ungulados cinegéticos: la producción de naturaleza como respuesta a las exigencias de la sociedad occidental del siglo XXI. Arbor, 193 (786): a417. doi: http:// dx.doi.org/10.3989/arbor.2017.786n4006

Recibido: 30 abril 2015. Aceptado: 04 febrero 2016.

RESUMEN: En este último siglo, ha quedado demostrado que, al menos en los países desarrollados, los espacios reservados para la práctica de la caza deportiva son los que han llegado hasta nosotros en las mejores condiciones de conservación, fundamentalmente gracias a la voluntad de propietarios y gobernantes que han deseado preservarlos de otras actividades humanas. Pero con una población mundial en continuo crecimiento y acontecimientos como el land grabbing, la sensibilización ecológica de la sociedad urbanita, la radicalización de la fractura económica de la sociedad y el abandono rural, entre otros, quizás estemos obligados a replantearnos el papel de la actividad cinegética. Quizás haya llegado el momento de que el mantenimiento de los espacios cinegéticos necesite ser rentable por sí mismo, para cualquier persona que quiera vivir y trabajar en ellos, en lugar de depender de la buena voluntad de algunos. Y quizás la producción de naturaleza pase a ser un negocio necesario.

PALABRAS CLAVE: Carne de caza; caza; conservación de la naturaleza profesionalizada; ganadería cinegética; gestión cinegética; granja cinegética; productores de naturaleza; ungulados silvestres.
BIG GAME VS WILD UNGULATE FARMING: NATURE PRODUCERS

\section{AS AN ANSWER TO THE 21st CENTURY REQUIREMENTS OF WESTERN SOCIETIES}

Copyright: () 2017 CSIC. Este es un artículo de acceso abierto distribuido bajo los términos de la licencia Creative Commons Attribution (CC BY) España 3.0.

ABSTRACT: In the last century, it has been shown that, at least in developed countries, the areas devoted to the practice of sport hunting are some of the best preserved and least altered by man, mainly because of the willingness of owners and rulers who wished to preserve them from other human activities. However, under a global scenario of world population growth and the rise of events such as land grabbing, environmental awareness of urban society, acute social economic fragmentation and rural abandonment, among others, we may be forced to rethink the role of the hunting activity. Perhaps the time has come for the maintenance of hunting areas to be profitable, for anyone who wishes to live and work in them, instead of relying on the good will of their managers. Perhaps the production of nature ought to be a necessary business.

KEYWORDS: Deer farming; game management; hunting; nature producers; professional nature conservation; venison; wild ungulate breeding; wild ungulates. 


\section{INTRODUCCIÓN AL CONCEPTO DE CAZA}

La actividad cinegética afecta a muchos y diversos ámbitos, gozando de la aprobación o el rechazo según se la contemple. Según de quién se trate puede ser: una afición, un pasatiempo, un deporte, un estilo de vida, una aventura, una excusa para viajar, una pasión, un sobresueldo, un medio de vida, el único sustento, una actividad necesaria, un control de poblaciones, un despropósito, una abominación, un mal menor con el que hay que convivir, un motor de desarrollo rural, una herramienta de gestión medioambiental, etc.

Incluso para los propios cazadores tratar de entender la caza desde una única perspectiva que explique todas sus particularidades de forma integradora, podría ser tan difícil como hacerlo en torno a las relaciones entre hombres y mujeres.

No obstante, si logramos distanciarnos de las circunstancias coyunturales y echar un vistazo con perspectiva prehistórica, nos resultará más fácil dar con esa "teoría unificada" de la caza, si existe.

Sin duda alguna, actualmente tenemos a nuestra disposición -gracias a Internet- más información que la que jamás ha tenido nadie en toda la historia de la humanidad. Sin embargo, ahora más que nunca, es necesario saber separar la información superflua, imprecisa o capciosa, de lo sustancial y veraz, y saber interpretarla adecuadamente.

De lo que no cabe duda es de que, a lo largo de los últimos cientos de miles de años, la caza ha supuesto una fuente de alimentación absolutamente fundamental. Tan solo en estos últimos 10.000 años, gracias a la agricultura y la ganadería, la caza ha ido perdiendo su protagonismo como medio de provisión de alimentos (Cassinello Roldán, 2013).

Mientras que la actividad agropecuaria ha ido colonizando el espacio y erradicando especies que compitieran con las domésticas seleccionadas para la producción del alimento elegido, las especies silvestres han ido quedando relegadas a aquellos espacios que no reunían las condiciones óptimas ni siquiera para una explotación agropecuaria, pasando a ser su caza (sobre todo en el caso de los ungulados silvestres) una actividad de ocio reservada primero a los gobernantes, posteriormente a la aristocracia y, muy recientemente, a toda aquella persona con poder adquisitivo para cubrir los altos costes que esta afición ha conllevado.

Dicho esto y antes de seguir con la argumentación, permítaseme un inciso. Para ser justos, deberíamos ser conscientes de que la actividad agropecuaria no es el monstruo exterminador de especies. Mucho más lo es el hombre moderno de los países desarrollados en sí mismo. En primer lugar, erradica las especies de los lugares donde se asienta, las ciudades, luego de los lugares donde desarrolla su actividad extractiva, comercial e industrial, minas, mercados, puertos, polígonos industriales, etc., y así sucesivamente. Sin embargo, a menudo oímos que es la actividad agrícola y ganadera la gran enemiga de la conservación de la naturaleza.

Si nos centramos en España, a lo largo del siglo XX y especialmente en sus últimas décadas, la caza ha sufrido un cambio radical nunca antes observado. Con los cambios sociales y económicos, la revolución industrial, la proliferación de los vallados ganaderos primero y cinegéticos después, y el advenimiento de la sociedad del bienestar, la caza ha pasado de ser el privilegio de la aristocracia y la alta burguesía o el salvavidas de las clases rurales más pobres, a convertirse en una de las aficiones "deportivas" con más federados. Esta nueva coyuntura facilitó en los años 60 del siglo pasado la mercantilización de esta atávica relación del hombre con las especies silvestres, favoreciendo con ello dos situaciones contrapuestas. Por un lado, la posible desaparición de las mismas en aquellos lugares donde han estado a libre disposición de la gente, y por otro, a menudo, su superabundancia en aquellos terrenos donde se las explota cinegéticamente.

Valga como muestra la gran diferencia que se puede observar entre dos regiones españolas limítrofes como son la Comunidad valenciana y la castellanomanchega, sin ir más lejos. Mientras que en la primera la agricultura intensiva, la industria y el aprovechamiento forestal llevaron casi al exterminio de los ungulados silvestres y actualmente la mayoría de los terrenos donde se suele practicar la caza mayor son públicos y libres, en la segunda, el abundante aprovechamiento agropecuario extensivo ha permitido una mayor supervivencia de estas especies, que han acabado aglutinándose en fincas valladas privadas donde se les ha podido contener, controlar y gestionar de forma privada, siendo actualmente donde se las caza principalmente. Esto ha llevado a modelos de gestión totalmente diferentes que han hecho de la caza una actividad con una relevancia muy distinta entre ambas regiones, con significados y connotaciones muy diferentes para los cazadores que, desde diferentes orígenes, la practican. Lógicamente, aún son mayores las diferencias que hay entre cazadores de distintos países o entre continentes. En este sentido la diversidad de cazadores va desde el que practica la caza de subsistencia de pequeños animales para sobrevivir en 
los trópicos (véase Vargas, Farfán, Duarte y Fa, en este mismo volumen) hasta aquel que practica la caza mayor en vacaciones para viajar, conocer mundo y dejar unas divisas en las poblaciones locales, pasando por las mil y una formas de vivir la caza.

Por otra parte, el incremento del abandono rural por parte de agricultores y ganaderos está facilitando el aumento descontrolado de las poblaciones de ungulados silvestres.

Llegados a este punto, podemos afirmar que la actividad cinegética ha quedado supeditada, a lo largo de la historia, fundamentalmente al uso que hemos hecho del territorio en función de nuestros intereses económicos.

Por tanto, para poder pronosticar cual podría ser el futuro de la actividad cinegética, con unas mínimas garantías de certidumbre, sería necesario intentar comprender cuál es la situación económica mundial y su relación con el medio rural.

\section{¿PARA QUÉ SE VA A NECESITAR EL SUELO A ESCALA MUNDIAL EN EL FUTURO?}

De entre todas las actividades humanas posiblemente la agricultura y la ganadería sean las que más terreno ocupan. Por tanto, deberíamos intentar ver cuál es la previsión del uso que estas actividades van a hacer del suelo.

El constante crecimiento de la población mundial haría pensar, en un primer análisis, que vamos a necesitar todos los pedazos de tierra posibles para cultivar alimentos. De esto trata la tan presente Seguridad Alimentaria que en los años 50 del siglo pasado en Europa motivó la creación de la Política Agraria Comunitaria (PAC) y que actualmente se mantiene en todas las agendas políticas internacionales. Incluso desde la crisis alimentaria de 2007-2008, a la luz del fenómeno mundial conocido como land grabbing (de Castro, 2012) parecería ser un problema mucho más grave de lo imaginado. Sin embargo, hay razones para pensar que esa urgencia no es tan acuciante y fundada como cabría pensar. O cuando menos, hay criterios dispares que nos invitan a la duda.

En Europa, si bien el consenso en torno a la PAC fue ayudar a agricultores y ganaderos para poder garantizar el suministro de alimentos a los ciudadanos europeos, en los años 80 se llegó a una situación de sobreproducción que cambió radicalmente la situación. La sobreabundancia de alimentos producidos en Europa, junto a la globalización de los mercados, los acuerdos de comercio internacional, el establecimiento de la sociedad del bienestar y la sensibilización de la ciudadanía ante la degradación medioambiental, entre otras cuestiones, hicieron que los objetivos de la PAC fueran cambiando. Se empezó a poner límites a la producción, se empezó a exigir una actividad agrícola y ganadera más respetuosa con el medio ambiente, se orientó al sector primario a diversificar sus producciones adaptándose a las demandas de los consumidores y a las exigencias de los mercados, se recortó el presupuesto y se acabaron por introducir el desacoplamiento de las ayudas respecto de la producción y la condicionalidad de la percepción de las ayudas al cumplimiento de medidas de carácter agroambiental. La evolución de esta situación ha contribuido, en estas últimas décadas, a un aumento del abandono progresivo de aquellos terrenos agropecuarios donde no se puede mantener una producción económicamente competitiva en este contexto de la globalización de los mercados, lo cual se ha agravado notablemente en estos últimos años con la crisis económica.

En el caso concreto de Europa los agricultores y ganaderos están sometidos a unos condicionantes productivos que no sufren el resto de productores extracomunitarios, a saber: alto valor de la tierra, elevada presión fiscal, salarios mínimos, seguridad social, prevención de riesgos laborales, bienestar animal, o un sin fin de prohibiciones en el uso de determinados productos o técnicas; alimentación animal, fertilizantes, insecticidas, fitosanitarios, zoosanitarios, hormonas, manipulación genética, etc. Sin embargo, no tenemos ningún problema en importar estos alimentos de países donde no solo no se exigen estas condiciones, sino que incluso a veces se producen mediante explotación infantil o de género y, ante esto, ni siquiera se ponen aranceles a su importación.

Y ante esta situación, los ciudadanos europeos, habida cuenta de las condiciones acordadas para la percepción de las ayudas económicas de la PAC, así como las restricciones impuestas a través de las políticas de protección de Espacios Naturales, como RED NATURA 2000, parecen estar más preocupados por la conservación de la fertilidad de la tierra europea y su biodiversidad que por la producción de alimentos en sí. De otro modo, las autoridades europeas a falta de subsidios públicos a la producción, en lugar de poner cada vez más exigencias a los agricultores y ganaderos europeos, deberían poner aranceles a la importación de alimentos de países donde no se cumple con esas mismas exigencias, o legislar de forma que facilitaran a los productores vender directamente sus productos 
a los consumidores; sin embargo, la legislación hace todo lo contrario, obliga a los productores a cumplir con unos trámites legales insufribles, mientras que pone todas las facilidades del mundo para que sean los intermediarios los que acaparen toda la cadena desde la producción hasta la venta al consumidor.

Por otra parte, en cuanto a la producción de alimentos, los avances tecnológicos alcanzados a lo largo de las últimas décadas han permitido que la productividad de las superficies agrícolas se haya multiplicado y que se haya definitivamente desligado de la tierra, siendo posible producirlos mediante cultivos hidropónicos bajo invernaderos (hasta en los tejados de rascacielos, por ejemplo) o mediante ganaderías intensivas bajo techo e incluso, como ya se ha anunciado y veremos en poco tiempo, la producción de proteína animal mediante su cultivo en laboratorio (Cultured Beef, Maastricht University, http://www.culturedbeef.net).

Con la generalización de la aplicación de estos avances tecnológicos a todas las superficies agrarias actuales es muy razonable pensar que sería suficiente para cubrir la demanda mundial de alimentos sin necesidad de seguir deforestando algunas zonas del planeta.

En resumen, quizás el problema de la seguridad alimentaria mundial sea tan solo una cuestión política y, efectivamente, lo más importante no sea la producción en sí de alimentos, sino luchar contra la desertificación, tratando de mantener nuestros suelos vivos y fértiles, mediante actividades sostenibles, al menos ecológicamente, como parece compartir la mayoría de la ciudadanía europea. Pero para ello habría que mantener gente en el medio rural que no pierda esa cultura agropecuaria y que pueda seguir haciéndose cargo de una adecuada conservación de estos espacios, produciendo alimentos bajo el estándar ecológico. Sin embargo, para que esto sea posible es necesario desarrollar una actividad económicamente rentable en el medio rural, de lo contrario el éxodo rural continuará y los campos y montes estarán cada vez más abandonados, agravando los problemas derivados de ello.

\section{EL CAZADOR VS. EL GESTOR CINEGÉTICO}

Ante esta situación, cuando algunos estudios económicos hablan de que la caza en España mueve más de 3.000 millones de euros al año (Garrido Martín, 2012), es decir, más dinero que el sector olivarero español (Interprofesional del Aceite de Oliva Español, 2009) o que la agricultura y la ganadería ecológicas juntas (Caracterización del sector de la producción ecológica española, 2013), cabría pensar que la caza como deporte podría formar parte de una de las soluciones. Por tanto, esta posibilidad nos exige estudiar más detalladamente cuál es la situación real de la caza deportiva en España.

A pesar de que son muchos los actores que intervienen en el vasto mundo de "la caza", casi siempre se tiende a verla desde la perspectiva del cazador, o sea, del usuario de la actividad, mientras que muy pocas veces se observa que para que ese usuario pueda disfrutar de esa caza es necesario que exista un terreno donde esos animales se críen, así como alguien que se encargue de que esos animales puedan subsistir en adecuadas condiciones y sin poner en peligro la vegetación y la biodiversidad ni las actividades de otras personas, agricultura, tráfico, riesgos para la salud, etc. Curiosamente, el responsable de todo ello no es el cazador, sino el titular del aprovechamiento cinegético, en principio, del propietario del terreno, aunque a menudo, este es el mismo cazador o grupo de cazadores que se hacen cargo de su propio coto privado o del coto municipal por el que pagan un arrendamiento, asumiendo todos los gastos como tributo que hay que pagar por practicar su afición.

Si nos ponemos en el lugar de este otro actor de la actividad cinegética observaremos nuevos matices. Por ejemplo, tanto si el terreno es de titularidad pública como privada, el hecho de que se dedique a la crianza y mantenimiento de estas especies solamente es posible en la medida en que se deja de utilizar para otros fines, lo cual, como mínimo, supone un coste de oportunidad, por no hablar de la amortización del capital en el caso de haber comprado esos terrenos, o de los impuestos de IBI y coto, o de los gastos de personal para el mantenimiento del espacio y las infraestructuras, o de los gastos por seguros para cubrir las posibles indemnizaciones en caso de daños a la agricultura o accidentes de tráfico, o incluso los gastos para el control de la población en el caso de que los cazadores no hagan la suficiente presión cinegética.

Visto desde esta perspectiva, nos damos cuenta de que para que la actividad cinegética subsista también es necesario que alguien viva y trabaje en el medio rural, es decir, que a alguien también le compense desarrollar esa actividad. Por suerte o por desgracia el arrendamiento cinegético de los espacios públicos es muy económico y no requiere un gran esfuerzo para ser cubierto por quien lo arrienda. El 5 de septiembre de 2011 se publicaron en el Diario Oficial de la Generalitat Valenciana no 6601, páginas 31382-31386, los datos referentes a la subasta del aprovechamien- 
to cinegético de 76 acotados de utilidad pública para los años 2012-2017. En total 52.818,88 hectáreas con un precio de salida total impuestos incluidos de $226.678 €$, o lo que es lo mismo, un precio medio de salida de 4,29 €/ha impuestos incluidos. Según Garrido Martín (2012) el precio medio pagado en España por arrendamiento de cotos de caza estaría en $15 € /$ ha. Extrapolando datos, si los 35 millones de hectáreas de acotados que hay en España se pagaran a ese precio, el importe total invertido por los cazadores en arrendamientos cinegéticos a los propietarios de los terrenos sumarían 525 millones de euros.

Entonces, si aceptamos como válido el montante global del dinero que mueve la caza en España según establecen estos estudios (más de 3.000 millones de euros/año), se podría decir que sólo el $15 \%$ del presupuesto de los cazadores llega a quienes se dedican a la cría de los animales o al mantenimiento de sus espacios, esto es, unos $648 € /$ cazador al año. Si las cifras son correctas y el número de cazadores es de 800.000 , como apuntan estos estudios, el resto de los aproximadamente $4.500 €$ de presupuesto, $3.825 € /$ cazador y año, iría a parar a equipo, armas, ropa, coches, perros, hoteles, viajes, taxidermia, etc.

Sin embargo, cualquiera diría que mantener una finca de caza debe ser un negocio muy lucrativo. Y si es de caza mayor todavía más. Pues bien, nada más lejos de la realidad. Aparte de los ajustados ingresos por la venta de derechos de caza, la gestión de los ungulados cinegéticos y su medio está plagada de trabas tanto administrativas como sociales.

Para empezar, son muchos los que condenan abiertamente la caza en vallados cinegéticos. Entre estos se incluyen algunos cazadores que defienden que la caza debe ser absolutamente natural sin prácticamente ninguna intervención humana que manipule el hábitat o las poblaciones de estos animales. Quizás esta visión romántica sea válida para los grandes espacios vírgenes de Canadá, Rusia y alguno más; pero en la Europa actual esto es poco menos que imposible. Por el contrario, otros, entre los que también se encuentran cazadores, motivados por la posibilidad de ganar mucho dinero en poco tiempo, apuestan por manejar a los animales como si de objetos de consumo rápido se tratara, criándolos en condiciones intensivas o comprándolos en granjas cinegéticas intensivas para su suelta e inmediata caza en cotos que ofrecen un entorno más o menos agradable, sin pararse a pensar que este tipo de "caza" es rechazada de plano por la opinión pública, perjudicando con ello a la imagen pública del conjunto de la actividad cinegética.
Tan es así que un grupo de científicos españoles ha propuesto la aplicación de un sistema de calidad cinegética certificada como herramienta que ayude a contener la actividad cinegética dentro de unos parámetros que garanticen la sostenibilidad ecológica de las especies de fauna y flora que viven en los espacios donde esta se desarrolla (Carranza y Vargas, 2007). Reconocen que es necesario que la caza sea viable económicamente $y$, sin embargo, se desestima para esta certificación no solo a los cotos intensivos, sino incluso a los cotos donde se refuerza la población con sueltas procedentes de granjas cinegéticas.

En este punto es necesario hacer, a modo de inciso, una reflexión. Si por coto intensivo entendemos el típico coto de caza, fundamentalmente de menor, donde se practica la caza comúnmente conocida como "de bote", estoy totalmente de acuerdo en que no se le conceda esa certificación de calidad cinegética. Pero si por coto "intensivo" (desafortunada palabra para nombrar el tipo de coto que voy a describir) entendemos aquel coto, fundamentalmente de caza mayor (donde a menudo se renuncia a aprovechar la caza menor, en favor de los depredadores naturales), constituido sobre un espacio natural bien conservado, donde se mantiene una población de ungulados silvestres por debajo de la capacidad de carga del medio, en el que puntualmente se sueltan algunos individuos de alto valor cinegético para satisfacer una demanda en firme y poder así alcanzar la rentabilidad económica del acotado, no puedo estar más en desacuerdo.

Esta salvedad se basa en dos hechos. En primer lugar, los propios científicos indican que, tratándose de fincas valladas, es necesario introducir variabilidad genética, lo que se entiende en el campo como "renuevo de sangre", periódicamente para evitar los indeseados procesos endogámicos. Sin embargo, el Real Decreto 1082/2009 de 3 de julio, por el que se establecen los requisitos de sanidad animal para el movimiento de animales de explotaciones cinegéticas, determina que son obligatorias unas pruebas sanitarias, las cuales requieren varios manejos espaciados en unos días, sobre los animales a trasladar (por ejemplo, la prueba de la tuberculina). En la práctica, estos manejos, si se realizan sobre animales totalmente salvajes, provocan un nivel de estrés que no solo puede llegar a alterar la prueba, sino que causa un porcentaje de bajas por peleas, traumatismos e infartos, absolutamente excesivo e intolerable. Por tanto, en la práctica, solo se puede cumplir esta norma con animales que estén acostumbrados a pasar por las instalaciones imprescindibles, es decir, con animales procedentes 
de granjas cinegéticas donde, desde pequeños, anualmente se les somete a este tipo de manejo sin que para ellos suponga mucho estrés. En segundo lugar, uno de los objetivos de la certificación es que la actividad sea económicamente viable; pero la premisa indiscutible es que el coto sea ecológicamente sostenible, para lo cual es imprescindible mantener una carga ganadera ajustada a la capacidad de carga del medio, nunca por encima. Sin embargo, hoy por hoy, en la España seca, a los precios que se está pagando la caza y la carne de la caza, esa rentabilidad económica es imposible sin ese refuerzo. $Y$ las perspectivas de futuro son que los ingresos por tasas de abate sigan disminuyendo, a tenor del incremento de la oferta, no solo por el aumento generalizado de las poblaciones de ungulados silvestres en toda España, sino también por el aumento de la oferta internacional. Por tanto, la viabilidad económica de los cotos de caza mayor, al menos desde el punto de vista del gestor cinegético, tiene un futuro muy incierto.

Por otra parte, no parece muy justo para el gestor cinegético que, por intereses públicos, se obligue a este tipo de espacios a una normativa mucho más estricta que a un solar urbano o periurbano y que, por otra parte, no se articulen medidas que permitan los ingresos necesarios para el mantenimiento de estos espacios. Resulta cuando menos curioso que, en el caso de cotos de caza, de fincas de caza, se hable de la viabilidad económica como de un objetivo, cuando para cualquiera que esté pensando en poner en marcha una empresa y requiera de financiación la viabilidad económica no es un objetivo, es una condición sine qua non, la premisa indispensable que hay que demostrar con un plan de empresa bien ejecutado sin el cual nadie se arriesgaría a invertir.

Son tales esas trabas sociales a las que me refiero que no solo algunos propietarios de fincas de caza no quieren que su actividad se relacione con las granjas cinegéticas, sino que incluso son muchos los propietarios de granjas de este tipo de especies que tampoco quieren tener nada que ver con la caza.

Vemos por tanto que esas trabas sociales, digamos sentimentales o ideológicas, conllevan otras de carácter técnico-normativo que afectan sustancialmente a lo económico.

Hablando del aspecto normativo, hasta la fecha toda la legislación en materia cinegética ha contemplado esta actividad como si dependiera de la extracción de un recurso natural de dominio público (la famosa res nullius). Este enfoque sería más acertado para la pes- ca en altura en aguas internacionales o para el aprovechamiento de poblaciones naturales que viven en espacios abiertos de titularidad pública, como puedan ser Parques Nacionales o cotos de caza municipales. Sin embargo, la realidad en Europa es que la mayor parte de los ungulados cazados se crían en fincas valladas de propiedad privada.

Se podría decir que con esa legislación lo que se pretende es garantizar la conservación de la vegetación y la biodiversidad. No obstante, lo más curioso es que si el propietario de esa finca la dedica a criar vacas o cualquier otro ganado doméstico no se le pone ningún límite a la carga ganadera que pueda mantener de forma natural ese espacio; es más, al parecer a partir de 2015 los ganaderos que quieran recibir las ayudas de la PAC por aprovechamiento de pastos tendrán que justificar una carga ganadera mínima de $0,20 \mathrm{UGM} / \mathrm{ha}$. Eso equivaldría a un ciervo/ha como mínimo, lo cual para cualquier responsable público de cotos de caza en más de media España supondría un absoluto despropósito e incluso un motivo para retirar la titularidad del coto de caza. Sin embargo, cuando se decide dedicar esa misma finca a criar especies cinegéticas todo cambia y la legislación le pone límites a la cantidad de animales que hay que tener y hasta al cómo, cuándo y cuántos animales debe se deben matar, meter o sacar. Es como si se entendiera que el propietario de esa finca fuese un inconsciente imprudente si cría especies cinegéticas, y un comprometido y responsable ciudadano digno de recibir subsidios cuando cría especies domésticas.

Ciertamente estamos hablando de biodiversidad, tanto vegetal como animal, lo cual resulta ser del interés público; y la administración, al igual que debe velar por que cualquier actividad humana no atente contra el medio ambiente, también en este caso lo debe hacer, sin duda. Sin embargo, cuando hablamos de cotos de caza, los condicionantes legales son mucho mayores que en cualquier otra actividad.

En definitiva, todos hablamos de sostenibilidad, sin embargo, a menudo nos olvidamos de que para que algo sea sostenible lo debe ser en primer lugar desde el punto de vista económico.

Desde la perspectiva del titular y gestor cinegético, se podría decir que la producción de caza mayor en España comparte con el resto de producciones primarias varios problemas:

1. Falta de profesionalización de los productores. La inmensa mayoría de los propietariostitulares de fincas de caza mayor no gestiona 
de forma profesional, sostenible y prioritaria el aprovechamiento de sus recursos cinegéticos, debido a que simplemente los contemplan como una actividad secundaria que ayuda un poco a la renta de su explotación ganadera, agrícola o forestal. En este sentido podemos distinguir tres supuestos.

En el caso de cotos gestionados por las administraciones públicas, estas someten las cacerías a sorteos o subastas públicas a precios de salida muy económicos con la idea de ofrecer un servicio social, siendo el objeto principal de estas cacerías el control de poblaciones.

En el caso de cotos sociales o zonas de caza colectiva (nueva denominación propuesta para la nueva Ley de Caza de Castilla-La Mancha) son casi exclusivamente los vecinos del pueblo donde está ubicado el coto los que organizan las cacerías, fundamentalmente para el disfrute de los socios del acotado sin pensar casi en el control de las poblaciones y mucho menos en el beneficio económico.

En el caso de cotos privados de caza la actividad productiva principal es, en la mayoría de los casos, la agropecuaria. En cuanto a la caza mayor, los propietarios disfrutan sus fincas como lugar de encuentro, esparcimiento y ocio, invitando ocasionalmente a sus amigos y contactos profesionales. Y en algunos casos, realizado esto, ceden el aprovechamiento cinegético restante a organizaciones de cacerías que sí que aprovechan profesionalmente esos recursos.

2. Como consecuencia de la situación anterior, los propietarios de fincas como productores de caza resultan ser unos productores totalmente atomizados y desestructurados, con intereses muy diferentes, que están a disposición de unos cuantos organizadores de cacerías que controlan la comercialización de la producción cinegética.

3. En el caso de cotos privados de caza dedicados exclusivamente a la actividad cinegética los costes de producción que soportan los propietarios son, al igual que para el resto de productores del sector primario español, tremendamente más altos que la mayoría de los productores extracomunitarios del mismo sector, de tal forma que no pueden competir con la oferta internacional. Tan solo algunos clientes que no pueden ausentarse de sus trabajos más de un par de días asumen el sobrecoste de cazar en España, a cambio de no tener que coger el avión y ausentarse cuatro o cinco días. Aun así, en estas fincas la actividad cinegética es menos lesiva en todos los aspectos que la ganadería tradicional.

4. Finalmente, todos se ven afectados por la problemática de la carne de caza, cuyo mercado está manejado por unos pocos exportadores que "marcan los precios en lonja", mientras que los productores, atomizados, no son capaces de defender los precios ya que, por otra parte, el consumo de carne de caza en España es totalmente anecdótico, y un porcentaje altísimo (alrededor del 90\%) de la carne se exporta, principalmente a Alemania a través de esos pocos exportadores. De ahí que prácticamente nadie se dedique a criar ciervos para su aprovechamiento cárnico, a diferencia de lo que ocurre en la inmensa mayoría del resto de países de la Unión Europea.

Dicho todo esto, ¿cabe pensar en el trabajo en torno a las especies cinegéticas como una actividad productiva económicamente rentable, que realmente sea un motor generador de puestos de trabajo en el futuro para el desarrollo sostenible del mundo rural? ¿o simplemente se mantendrá por el caprichoso deseo de alguien con dinero suficiente como para dilapidarlo en su afición?

\section{EL FUTURO DE LA CAZA COMO ACTIVIDAD ECONÓMICA}

Gracias a los estudios realizados por la Real Federación Española de Caza (La situación de la caza en España (IV): daños, cultivos y caza, 2010) y por su Fundación para el Estudio y Defensa de la Naturaleza y la Caza (FEDENCA) (Garrido Martín, 2012), nos podemos hacer una idea de la situación del sector cinegético en España. De los datos aportados en dichos estudios, llaman poderosamente la atención dos cuestiones en concreto. Primero, desde hace aproximadamente dos décadas el número de cazadores no ha dejado de disminuir. Y segundo, desde que organismos como la Junta Nacional de Homologación, el Instituto Nacional de Estadística o la Real Federación Española de Caza han venido recopilando datos (ver Garrido, 2011), se ha constatado que las poblaciones de ungulados silvestres no han parado de aumentar; a un ritmo del $10 \%$ anual en los últimos años. Todos sabemos de la colonización de nuevos territorios por parte de corzos, ciervos, machos monteses y jabalíes. Así como del aumento de 
los accidentes de tráfico y los daños a la agricultura causados por estas especies.

En suma, ante una oferta cada vez mayor, el número de demandantes no deja de disminuir. Esto, sin duda, no solo plantea interrogantes, sino que también nos habla de futuros problemas. Por un lado, no es descabellado pensar que podría llegar el día en que la oferta exceda en tanto a la demanda que la inmensa mayoría de los cazadores no estén dispuestos a pagar nada por cazar a un animal. Por otro lado, en algunas zonas ya hemos llegado a un exceso tal de animales silvestres sueltos por el monte que la administración pública tiene que pagar a cazadores para que controlen las poblaciones (aunque esto solo sea fruto de una decisión política contraria a la economía), como ya lo están haciendo a través de agentes medioambientales en muchas zonas de España para evitar los daños a la agricultura, los accidentes de tráfico, el riesgo de transmisiones de enfermedades o incluso el peligro que algunas poblaciones están causando a infraestructuras públicas, como el caso de los conejos en las vías del AVE.

Podríamos decir que la reversión de esta tendencia ya es un objetivo de interés público. De no ser así, la proliferación generalizada de estas especies se convertirá en la pesadilla de las administraciones públicas.

Y esto no es un problema exclusivo de España. La revista Time del 9 de diciembre de 2013 dedicó su portada al siguiente titular: America's Pest Problem: Why the rules of hunting are about to change, dedicando varias páginas a analizar el problema del incremento de las poblaciones de especies silvestres y la necesidad de controlar esas poblaciones mediante su caza.

Esto no augura un futuro prometedor para la comercialización de la actividad cinegética tal como la hemos conocido estos últimos años. Los años dorados de la comercialización de la caza han pasado. La globalización de los mercados y la facilidad para viajar permiten que la oferta internacional, mucho más económica que la española, esté al alcance de la mano de muchas más personas, afectando muy negativamente al sector cinegético español.

Hoy en día es fácil encontrar safaris de una semana a África para cazar varios animales por unos 2.000 $€$. No es de extrañar que muchos cazadores de caza mayor, ante esta oferta, se pregunten si vale la pena gastarse esos $2.000 €$ en un día de montería o irse una semana a Sudáfrica, por ejemplo. O cacerías para el control de poblaciones en Australia o EEUU.
A la luz de estos datos básicos, para aquellos que se dedican a criar estas especies y los espacios que ellas ocupan la perspectiva no puede ser peor. De seguir esta tendencia no solo se cerrarían los cotos comerciales, sino que aquellos que conseguían una mínima renta, que les ayudaba a amortiguar los gastos de la finca, también la van a perder, y la pérdida de puestos de trabajo en este tipo de fincas se sumará al de las ganaderas, agravando aún más si cabe el despoblamiento rural, con la consiguiente repercusión negativa para la conservación del medio ambiente.

En definitiva, o destinamos fondos públicos al mantenimiento de este tipo de "reservas biológicas" de interés público, o conseguimos un alto precio por la carne, o reforzamos la renta cinegética con la suelta selectiva de ejemplares de alto valor cinegético, o concurrimos a un mercado libre de servicios ambientales, o convertimos nuestras fincas en parques turísticos, o tenemos que echar mano a una mezcla de todas estas posibles salidas, o tendremos que abandonar para a continuación vender las fincas que acabarán en manos de los multimillonarios extranjeros. Y mientras seguirán pasando de mano en mano mientras que quede alguien dispuesto a enterrar su fortuna en ellas.

Dicho esto, es necesaria otra reflexión. Como ya hemos apuntado en el apartado anterior, no todos los acotados son iguales ni tienen por qué serlo. Tenemos que distinguir tres escenarios muy diferenciados:

- Primer escenario. Una parte importante de la producción de caza mayor en España se desarrolla en espacios donde a menudo las únicas actividades que se desarrollan son la forestal y la ganadera a lo sumo. En estos terrenos la "actividad cinegética" es residual, realizándose solo por ocio y para el control de poblaciones. Son terrenos cuya titularidad a menudo está en manos de las administraciones públicas, locales y autonómicas fundamentalmente, como los Montes de Utilidad Pública, los Espacios Naturales, las Reservas Nacionales de Caza, o como sería el caso de los Parques Nacionales (donde se dice que no se puede cazar, pero que en realidad esa actividad la desarrollan - pagados por todos los españoles- los funcionarios, para el control de poblaciones) ocupando una superficie muy considerable.

- Segundo escenario. Los acotados surgidos de la agrupación de terrenos pertenecientes a pequeños y medianos agricultores e incluso mon- 
tes municipales, que son fundamentalmente de caza menor. En estos acotados las especies de caza mayor suponen un ataque directo contra los cultivos, por lo que en teoría deberían ser objeto continuo de control, aunque no se lleva a la práctica de forma eficiente provocando daños a la agricultura y accidentes de tráfico, originando sobrecostes a las asociaciones de cazadores que no están dispuestos a asumir.

- $\quad$ Tercer escenario. Los cotos privados de caza, los cuales son los grandes productores de especies cinegéticas. En estos a menudo se alternan las producciones agropecuarias domésticas con las cinegéticas, siendo solo unos pocos los que se dedican en exclusiva a la actividad cinegética comercial. Y finalmente, también hay que tener en cuenta a las granjas cinegéticas, que en muchos casos están asociadas a estos cotos privados de caza.

Estas diferencias explican los problemas que en 2013 y 2014 han surgido en Castilla-La Mancha como consecuencia del intento de la administración pública por fiscalizar esta actividad, obligando a rehalas, secretarios y muleros a darse de alta en la Seguridad Social. Sea como fuere, esta situación tiene una solución difícil que solo se podría arreglar mediante una adecuada legislación de caza donde se diferencien unos y otros acotados, como también se diferencia el uso que se le da a un vehículo si es para uso personal y privado o para realizar una actividad económica.

En cualquier caso, dada la importante economía que mueve y las implicaciones medioambientales que conllevaría su desaparición, es urgente saber por qué cada vez hay menos cazadores.

En esta línea, Ilama la atención que, mientras en España ocurre esto, en países como EEUU y Alemania la tradición cinegética se sofistica y enriquece con el paso de los años, aumentando el número de cazadores. Buscando diferencias quizás lo más llamativo sea que en los países donde se transmite de generación en generación la pasión por la caza esta esté muy ligada al aprovechamiento y consumo de la carne cazada, mientras que en España no existe esa tradición. En los primeros la caza se practica principalmente de forma individual o a lo sumo con un amigo, mediante las modalidades de rececho y aguardo, llevándose la pieza cazada a casa para llenar el congelador de carne. Sin embargo en España la caza tiene un carácter social mucho más marcado, siendo toda clase de cacería colectiva, ganchos, monterías, batidas, tiradas, ojeos, e incluso competiciones, las modalidades más practicadas, donde el componente social, de relaciones, de negocios o simplemente de estar un rato con los amigos es más importante que otra cosa y la carne es lo de menos, al punto de que, en muchos casos, se queda en el campo o incluso se llega a tirar a un vertedero, como por desgracia ocurre en descastes de conejos o en tiradas de palomas, por ejemplo.

Esto es un hecho, como también lo es que en España la carne de caza tiene el valor económico más bajo de toda la Unión Europea. Mientras que en el resto de Europa el precio medio pagado en campo por la carne de ciervo-gamo, está por encima de los $6 €$, pagándose en varios países a más de $10 € / \mathrm{kg}$ de canal limpia (Kotrba y Bartos, 2010), en España, sin embargo, la carne de ciervo se ha venido pagando entre 1 y $2 € / \mathrm{kg}$ de canal con piel. Si entre el oreo y la piel se pierde aproximadamente un $12 \%$ del peso, el precio equivalente de la canal limpia y oreada sería tan sólo un $13,6 \%$ más caro. O sea, entre 1,136 y $2,272 € / \mathrm{kg}$ de canal limpia. De ahí hasta los 6-8-10 €/kg, sin duda hay un margen incomprensible.

El cómo y porqué hemos llegado a esta situación quizás sea importante, no por buscar culpables, lo cual no tendría mucho sentido ni tampoco arreglaría nada, sino por descubrir los errores para no incidir en ellos y poder mejorar la situación.

$\mathrm{Si}$, como parece, una de las causas probablemente más importantes de que se vaya perdiendo nuestra rica tradición cinegética es esa falta de cultura por el aprovechamiento de la carne, quizás lo que deberíamos hacer es preguntarnos por qué no le damos valor a estas carnes, cuando, por contra, hay otros países donde sí que se les da.

\section{EL VALOR DE LA CARNE DE CAZA}

La primera razón por la que no se le da valor a la carne de caza es la falta de conocimiento. En España a todo el mundo le suena que la carne de caza es una carne muy fuerte con mucho sabor y la mayoría que la ha probado la asocia a guisos muy pesados, con chocolate, calderetas, etc. Incluso cuando le propones a alguien comerla a la plancha vuelta y vuelta, se extraña y pregunta: ¿pero eso no es peligroso?, ¿no hace falta cocinarla mucho?

La realidad es que la mayoría de los españoles que han probado la carne de caza, casi con seguridad, lo han hecho de un animal que ha muerto acosado por perros, práctica habitual para asegurar el control de las poblaciones de ungulados silvestres, probable- 
mente de varios tiros, que incluso le han reventado el estómago o los intestinos y que hasta que ha sido eviscerado y refrigerado han pasado unas cuantas horas. Sin duda, este tipo de carne tiene una contaminación hormonal y microbiológica que no solo afecta a su disponibilidad para el consumo, sino que la empapa de malos sabores e incluso modifica su textura al punto que la pueden hacer desagradable para cualquiera. Pero ¿cuál es la realidad en torno a la carne de caza?

\section{La carne: cantidad vs. calidad}

¿Qué lugar ocupa la carne de caza en el mundo?, ¿cuál es su verdadero valor? Actualmente se estima que se producen más de 300 millones de toneladas de carne (figura 1), de las cuales más del $80 \%$ es producida por únicamente tres o cuatro especies domésticas: vacuno, porcino y aves de corral (figura 2). Esto solo es posible gracias a la cría superintensiva de estas especies (figura 3 ).

Figura 1. Producción global de carne. 1961-2012.

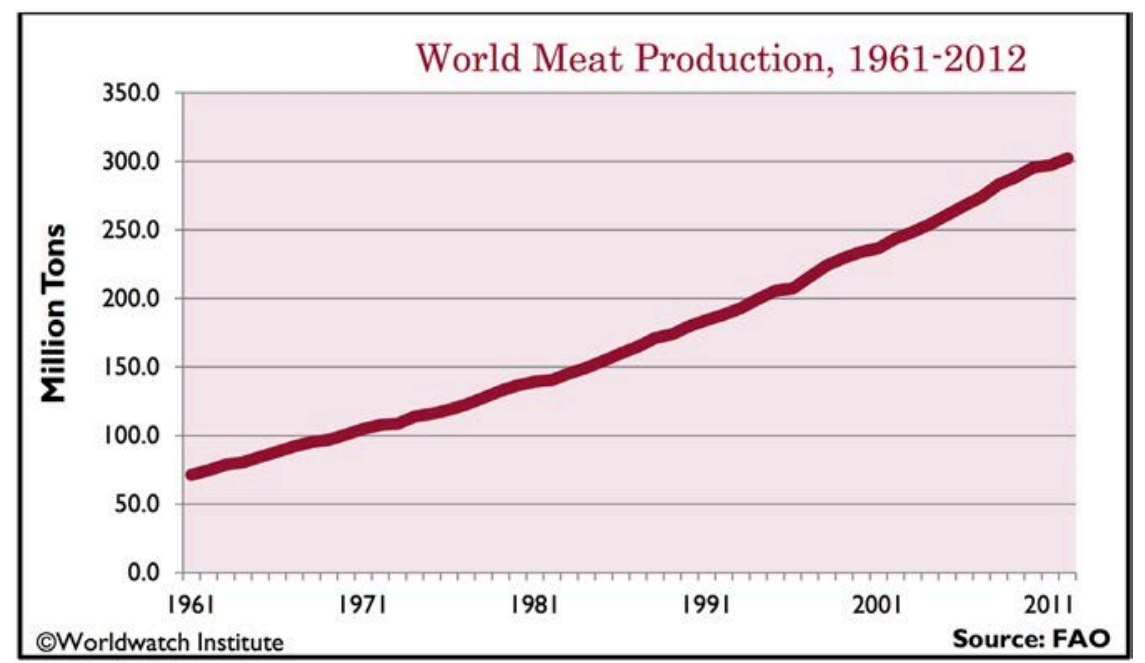

Fuente: FAO

Figura 2. Consumo global de carne por tipos. 1961-2025. Entre el 80 y el $90 \%$ de toda la carne producida en el mundo proviene de tres o cuatro especies domésticas: vacuno, porcino y aves de corral (pollos y pavos). Cifras en millones de toneladas.

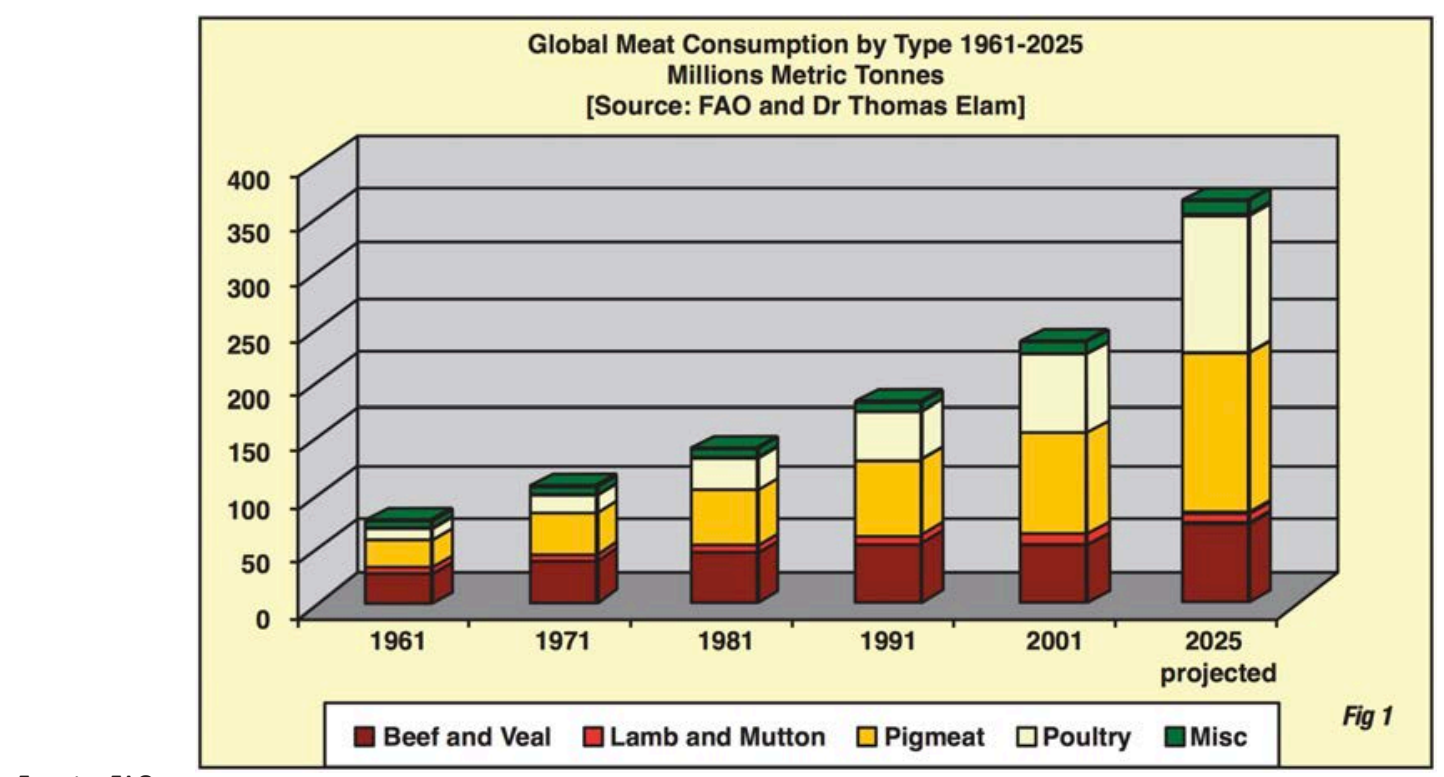

Fuente: FAO. 
Figura 3. Cría intensiva de especies domésticas.

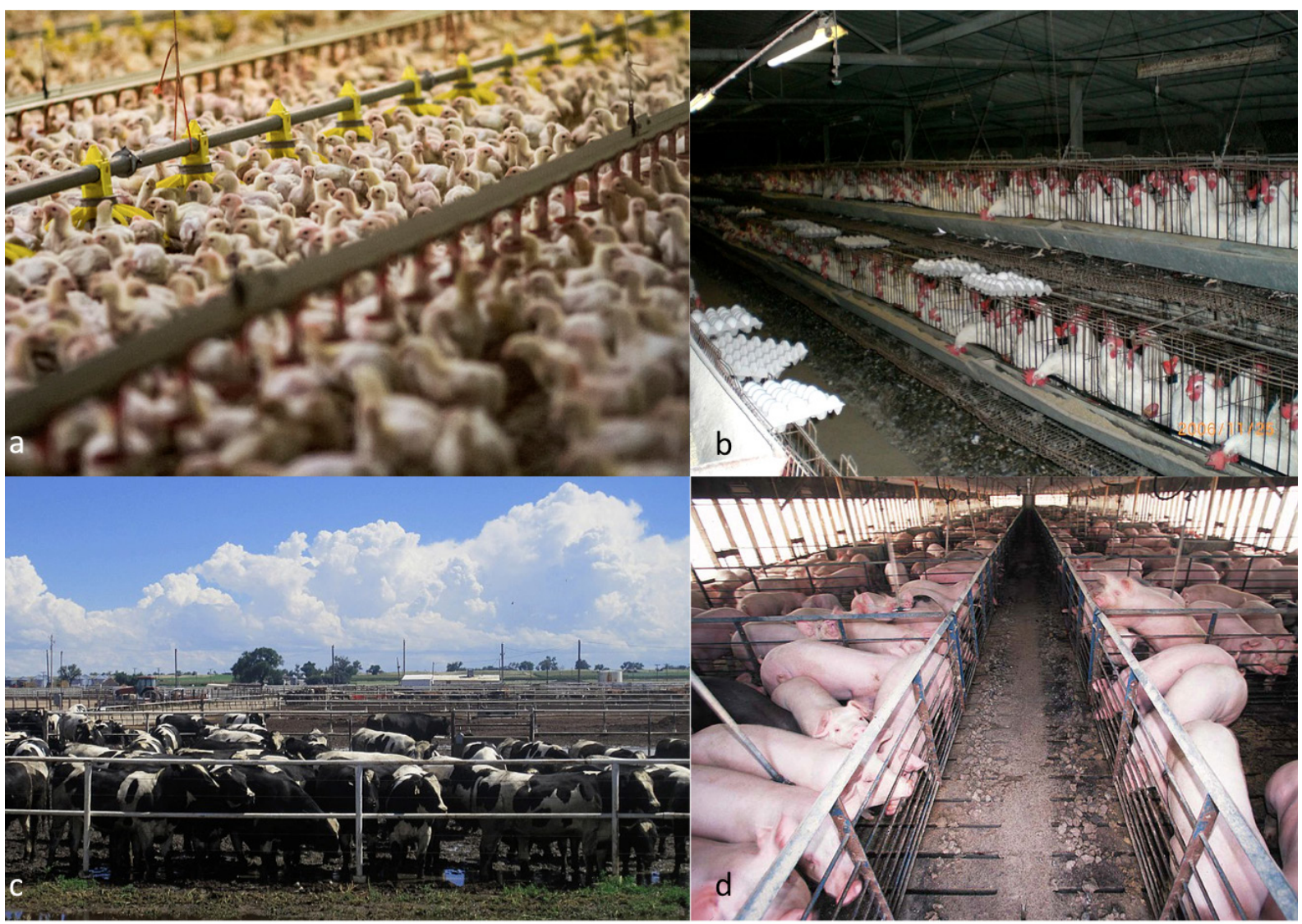

Fuente: Imágenes bajo licencia pública de Wikimedia Commons. Autores: a) Shpernik088, b) ITamar K., c) Billy Hathorn, d) desconocido.

Tenemos que ser conscientes de que las especies principalmente consumidas han sido objeto de un manejo intensivo que ha acabado por romper su relación ancestral con el medio natural que ocupaban. Por otro lado, las especies de ganados domésticos, vacas, cerdos, ovejas, cabras y pollos, han venido siendo seleccionadas desde hace miles de años para las diferentes producciones que nos han interesado, lo cual ha llevado a diferenciaciones morfológicas importantes, con unos índices de producción absolutamente antinaturales (figura 4).

Sin embargo, los ungulados silvestres han mantenido con el medio que ocupan una relación natural basada en milenios de coevolución, lo cual facilita la estabilidad y diversidad del ecosistema, haciendo a los animales mucho más rústicos y resistentes a las enfermedades, y mucho más respetuosos con el medio ambiente y su biodiversidad, que las especies de ganado tradicional. Y por otro lado, como los ungulados silvestres nunca han sido seleccionadas para la producción de carne, las tasas de crecimiento y conversión de pienso en carne son increíblemente inferiores, al igual que la calidad de la conformación de las canales. Muy al contrario, de forma natural los ungulados cinegéticos han sido seleccionados para ser "atletas" listos para la huida, por lo que, por lo general, mantienen unos niveles de grasa muy inferiores a los de las especies domésticas lo cual convierte a estas carnes en especialmente recomendables para las dietas hipocalóricas o para las personas con problemas de colesterol (tabla 1). Por otra parte, tienen unos niveles de proteínas, hierro y otros minerales muy superiores a los de las carnes de ganados domésticos tradicionales, lo cual las convierte en especialmente aptas para ancianos y deportistas. Estos valores nutricionales fundamentalmente, más que sus cualidades organolépticas, son los que tenemos que tener en mente a la hora de plantear la cría de especies silvestres, la comercialización y el consumo de la carne de caza.

En cualquier caso, son cuatro los factores que determinan la calidad de una carne, a saber: 
Figura 4. Selección de diferentes especies domésticas para diferentes producciones.

\section{BOVINOS}

a

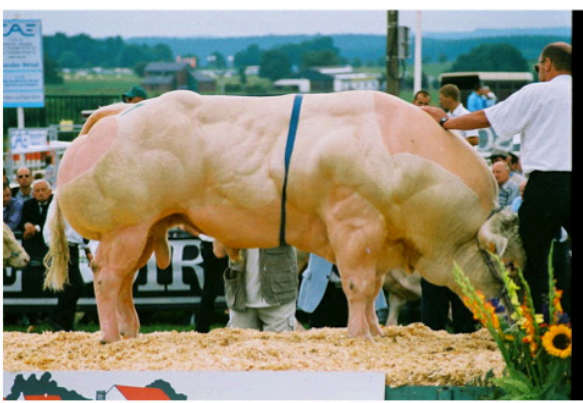

carne

Tabla 1. Cualidades nutricionales de la carne según especies. b

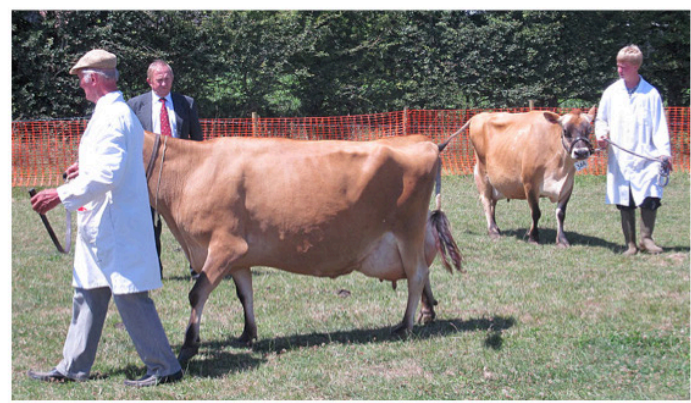

CAPRINOS

\section{leche}

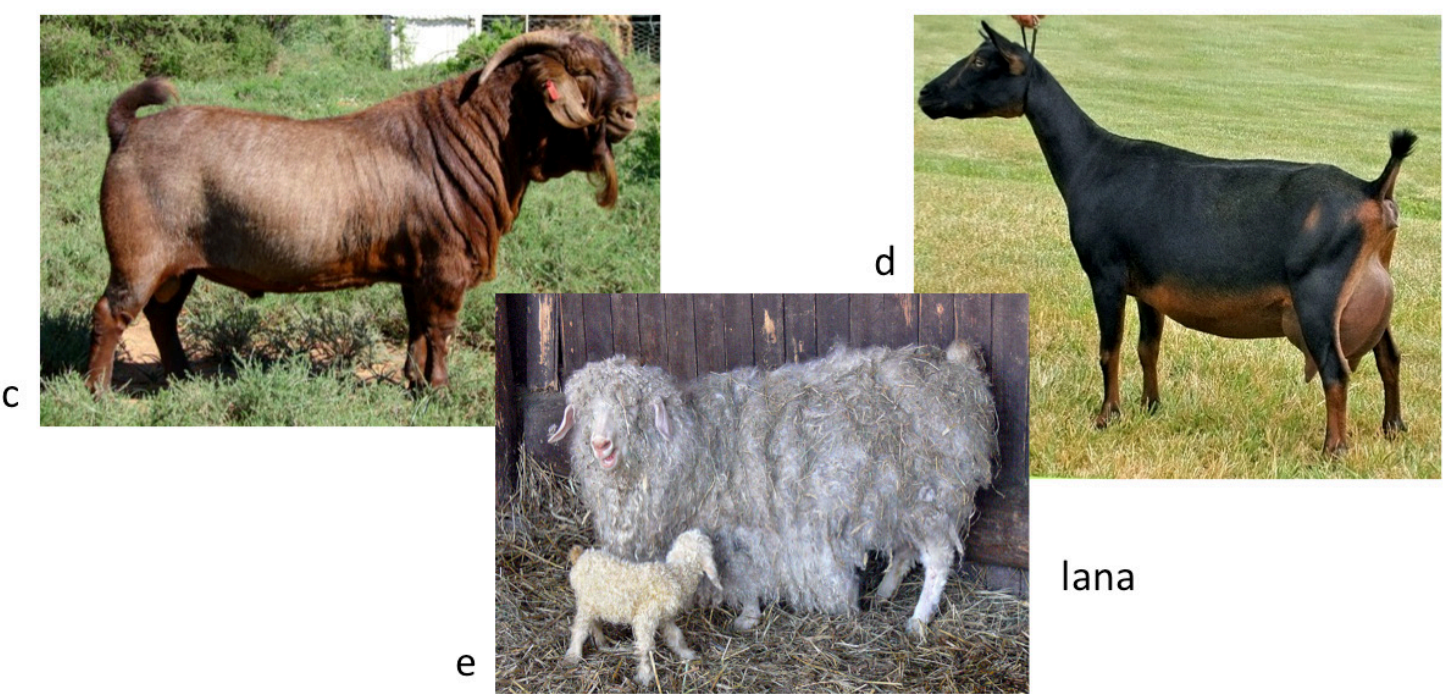

Fuente: Imágenes bajo licencia pública de Wikimedia Commons. Autores: a) Mastiff, b) Man vyi, c) NoFeaR, d) Jmkarohl, e) Stefan Walkowski.

\begin{tabular}{|l|c|c|c|c|c|c|}
\hline Especie & $\begin{array}{c}\text { KCalorías } \\
\text { (por 100g) }\end{array}$ & $\begin{array}{c}\text { Músculo } \\
\text { (en \%) }\end{array}$ & $\begin{array}{c}\text { Proteína } \\
\text { (en g) }\end{array}$ & $\begin{array}{c}\text { Grasas } \\
\text { (en \%) }\end{array}$ & $\begin{array}{c}\text { Huesos } \\
\text { (en \%) }\end{array}$ & $\begin{array}{c}\text { Colesterol } \\
\text { (en mg) }\end{array}$ \\
\hline Ciervo & $90-120$ & $70-79$ & $20,6-22$ & $2,4-5$ & $14-25$ & $45-50$ \\
\hline Vacuno & 350 & $50-66$ & -- & $16-37$ & $13-18$ & 80 \\
\hline Ovino & 270 & $48-64$ & -- & $14-38$ & $14-22$ & 70 \\
\hline Porcino & 330 & $53-67$ & -- & $22-38$ & $9-11$ & 90 \\
\hline Caballo & 108 & -- & 20,6 & 2,7 & -- & 54 \\
\hline
\end{tabular}

Fuente: Corell, 1994; Anuario de Estadística Agroalimentaria 2006.

1) La especie animal. Sin duda todos podemos distinguir entre la carne de pavo o pollo y la de cerdo o vacuno. Ya hemos visto en la tabla anterior los datos.

2) Selección y métodos de crianza y alimentación. Gracias a estas técnicas hemos conseguido carnes muy diferentes dentro de una misma especie, como ocurre con la del cerdo ibérico o la del Kobe, con una cantidad de grasa intramuscular mucho mayor que la que existe en otras razas de sus mismas especies (figura 5). Esto supone unas diferencias extraordinarias en cuanto a cantidades porcentuales de calorías, colesterol, proteínas, etc. 
Figura 5. Aspecto de la carne de ciervo (izquierda) y la de Kobe (derecha).

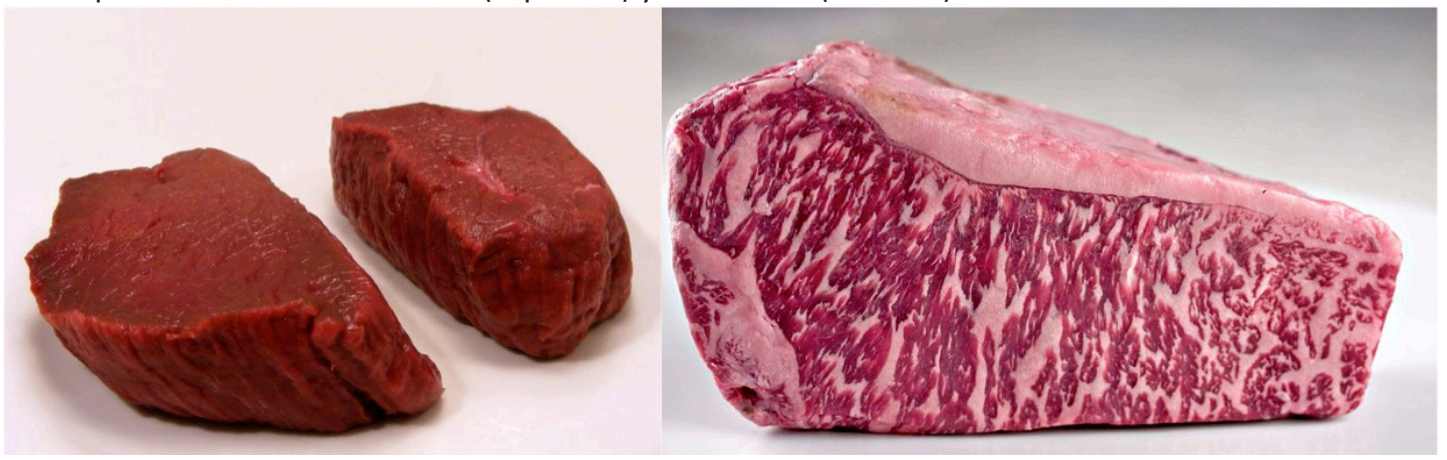

Fuente: Imágenes bajo licencia pública de Wikimedia Commons. Autores: FotoosVanRobin (izq.), H. Alexander Talbot (der.).

Dentro de una misma especie el sistema de manejo y alimentación también influye en la calidad de la carne, no es lo mismo alimentar a un animal a base de piensos compuestos procedentes del reciclado de los subproductos de la industria agroalimentaria, incluso con harinas elaboradas con restos cárnicos, mientras está estabulado (como de hecho se permite en países extracomunitarios aunque en EU esté estrictamente prohibida desde el año 2000 como consecuencia de la EEB), que alimentarlo pastando en praderas naturales sin contaminantes químicos, ni manipulación genética, ni tratamientos hormonales y además haciendo ejercicio (figura 6).
Incluso si el animal ha sido criado en el campo, tampoco tiene nada que ver la carne de aquellos animales que han sido criados aportándoles piensos compuestos a lo largo de todo el año o de forma importante durante los cuatro a seis meses de escasez (esencialmente el verano en España y el invierno en los países del norte de Europa), de la de aquellos animales que, por haberse criado en grandes superficies (varios cientos o miles de hectáreas) y con cargas ganaderas dentro de la capacidad de carga del terreno, han podido comer lo que el campo y la naturaleza les ha ofrecido en cada época del año de forma totalmente natural, como podría ser el caso de los cotos tradicionales de caza mayor en España.

Figura 6. Diferentes tipos de crianza: doméstico intensivo (a), doméstico extensivo (b), ciervo de crianza (c) y ciervo silvestre (d).

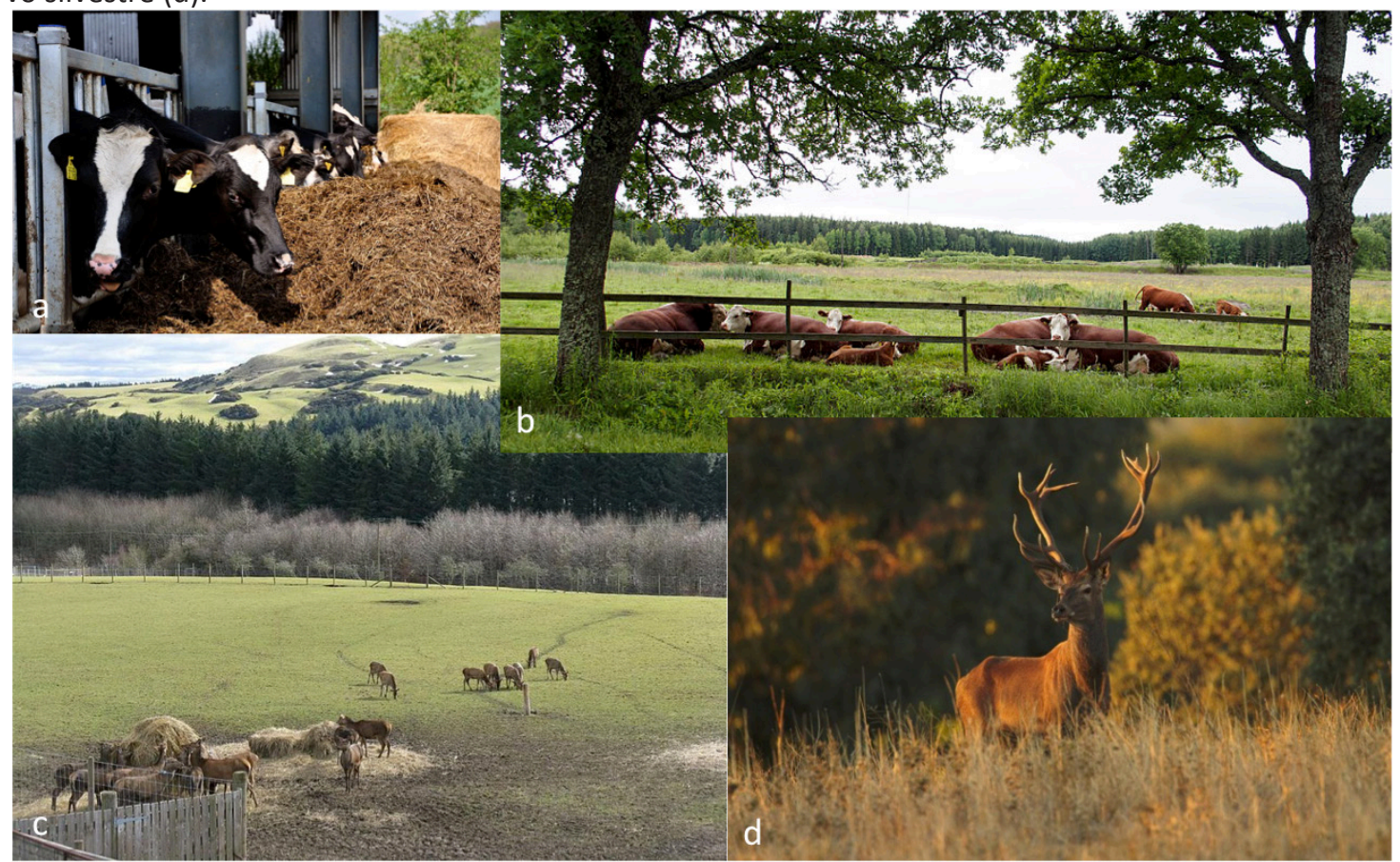

Fuente: Imágenes a, b y c bajo licencia pública de Wikimedia Commons. Autores: a) sacratomato_hr, b) Kotivalo, c) M J Richardson, d) Pedro Corell 
3) Las condiciones ante mortem. También influyen en la calidad de la carne las circunstancias que vive el animal previas a la muerte. Una misma especie animal, criada en las mismas condiciones, da una calidad de carne muy diferente en función de las condiciones en las que ha muerto. No tiene nada que ver la de una ternera sacrificada en el matadero con la de un toro lidiado en la plaza, a pesar de que sean hermanos y se hayan criado en la misma dehesa. Como tampoco es lo mismo un venado cazado en montería que uno cazado a rececho de un certero disparo en la cabeza o cuello sin que el animal se haya estresado por la presencia del cazador. Aparte de lo ya comentado en el párrafo segundo del apartado dedicado a el valor de la carne de caza, un animal que ha sido acosado y obligado a hacer ejercicio físico antes de su muerte habrá quemado la mayor parte del glucógeno de sus músculos y la carne que nos llegará tendrá un, no deseable, acúmulo de ácido láctico.

4) El manejo y tratamiento que se le haya dado a esa carne después de sacrificado el animal. No tiene nada que ver un ciervo cazado en montería que ha sido eviscerado entre cuatro y seis horas después de su muerte, con temperaturas exteriores superiores a $20 \circ \mathrm{C}$, que un ciervo que ha sido eviscerado y refrigerado a 2-3ㅇ $\mathrm{C}$ en menos de veinte minutos después de haber sido cazado.

Por todo lo dicho, a mi juicio, la rentabilidad de las explotaciones de cría de ungulados cinegéticos no debería estar basada en la búsqueda de un mayor y más rápido crecimiento de los animales para la producción de mejores canales o más cantidad de carne, sino en el mayor precio de la carne por sus valores nutricionales y naturales, libres de químicos de síntesis.

Si además tenemos en cuenta el escasísimo volumen que la carne de los ungulados silvestres representa sobre el total de carne producida, nos daremos cuenta de que no haría falta mucho para que la demanda superara en mucho a la oferta.

Me explico. En España el consumo per cápita al año es de $52 \mathrm{~kg}$ de carne aproximadamente, es decir, un consumo semanal de $1 \mathrm{~kg} /$ persona (Presentación de los datos de consumo alimentario en el hogar y fuera del hogar en España 2012). Si tan sólo el 4,9\% de la población española (2,3 millones de habitantes) consumiera $125 \mathrm{gr}$ a la semana ( $1 / 8$ del total de la carne consumida) no habría suficiente oferta en toda España para atender la demanda interna de este tipo de carne y no se podría exportar nada; esto es así porque el promedio de ungulados cazados anualmente no llega a 500.000 (Garrido, 2011), lo que a $30 \mathrm{~kg}$ de carne aprovechable por canal supondrían 15.000 toneladas de carne de caza. Sin duda, el potencial crecimiento de esta actividad es enorme.

\section{CONCLUSIÓN}

Por todo lo dicho estoy convencido de que la gestión del medio natural y más concretamente la cinegética va a desempeñar un papel imprescindible, en donde la implicación de los cazadores cada vez va a ser más necesaria para el control de las poblaciones en aras de la preservación de la biodiversidad, la lucha contra los incendios, la prevención de daños a la agricultura, así como la disminución de los riesgos de accidentes de tráfico y transmisión de enfermedades.

No obstante, dada la globalización de la comercialización de la caza, el aumento de las poblaciones silvestres, las presiones sociales anticaza y la paulatina pérdida de la afición cinegética, en España es absolutamente necesario que sepamos reconocer la carne procedente de las especies cinegéticas como el "caviar del campo", que lo es, y seamos capaces de ponerla en valor y promocionarla. No hacerlo sería desaprovechar un recurso valiosísimo, tanto en sí mismo como por las repercusiones que conlleva su desaprovechamiento.

Para ello será necesario que implementemos protocolos de actuación para el adecuado sacrificio de los animales durante la acción de caza, así como los medios necesarios para su saca del monte y el correcto manejo post mortem de los cuerpos para garantizar la máxima calidad de la carne. También serán imprescindibles las certificaciones de ámbito nacional oportunas que permitan diferenciar unas y otras carnes (por ejemplo, calidad rececho libre de contaminantes y calidad montería), ofreciendo al consumidor la garantía de lo que está comprando. Por otra parte, también sería necesaria una adecuada trasposición del reglamento (CE) no 853/2004 para que los productores no tengan más trabas legislativas autonómicas y puedan vender directamente al consumidor la carne de estas especies, o bien que los antiguos mataderos o carnicerías de los pueblos pudieran trabajar este tipo de carnes.

Dicho todo esto, y cayendo en la cuenta del esfuerzo personal que tanto cazadores como gestores cinegéticos y propietarios rurales tienen que soportar, y recordando el volumen generado por la caza en su conjunto, me pregunto ¿qué no llegaría a generar la caza en España si cazadores, gestores cinegéticos y propietarios rurales pudieran beneficiarse económicamente de la comercialización de la carne? De esta forma, los inputs del mundo rural pasarían de prove- 
nir del ocio caprichoso de los, cada vez menos, cazadores, al gasto necesario en alimentación saludable de la creciente población urbana en los mercados de mayor poder adquisitivo, ayudando por tanto a reducir la brecha económica entre ambas esferas.

Por consiguiente, en este siglo XXI que estamos iniciando la gestión de las especies cinegéticas y su medio natural necesita superar el concepto de aprovechamiento sostenible y pasar a ser contemplado, ya con una mentalidad proactiva, como producción de naturaleza. Así, junto con el turismo de naturaleza y el cinegético, podrían ser el paradigma de actividad productiva sostenible que permita la fijación de po- blación activa fuera del ámbito urbano, garantizando la conservación de la naturaleza y ofreciendo una esperanza para la incorporación de muchas regiones del tercer mundo al desarrollo económico global.

Mientras la conservación del medio ambiente dependa del altruismo de unos pocos, o de que aún quede alguien a quien le compense pagar una fortuna por practicar su afición, o de subvenciones públicas, dicha conservación no estará garantizada. Por el contrario, en el momento en que la conservación del medio ambiente sea una actividad económicamente rentable en sí misma, habrá un ejército de buenas personas dispuestas a vivir de ello y habremos ganado la batalla de la conservación.

\section{BIBLIOGRAFÍA}

Anuario de Estadística Agroalimentaria 2006. Datos de 2004, 2005 y 2006 (2006). Madrid: Ministerio de Agricultura, Pesca y Alimentación. Disponible en: http:// www.magrama.gob.es/estadistica/pags/ anuario/2006/AE_2006_Completo.pdf

Caracterización del sector de la producción ecológica española: valor, volumen y mercado y evaluación del impacto del comercio electrónico en la producción ecológica española (2013). Madrid: Ministerio de Agricultura, Alimentación y Medio Ambiente.

Carranza, J. y Vargas, J. M. (eds.) (2007). Criterios para la certificación de la calidad cinegética en España. Cáceres: Publicaciones de la Universidad de Extremadura.

Cassinello Roldán, J. (2013). La caza como recurso renovable y la conservación de la naturaleza. Madrid: CSIC y Los Libros de la Catarata.

Castro, P. de (2012). Hambre de tierras. Alimentos y agricultura en la era de la nueva escasez. Madrid: Eumedia.
Corell, P. (1994). El ciervo rojo, su ganadería y utilidad en áreas deprimidas. [Trabajo de fin de carrera inédito]. Universidad Politécnica de Valencia: Valencia.

Garrido, J. L. (2011). Estimación de aprovechamientos cinegéticos en España por especies y comunidades autónomas. Temporadas 2000-2010. Madrid: FEDENCA-Real Federación Española de Caza.

Garrido Martín, J. L. (2012). La caza. Sector económico. Valoración por subsectores. Madrid: FEDENCA- Real Federación Española de Caza.

\section{Otros recursos}

Aceites de oliva de España. Disponible en: https://www.aceitesdeolivadeespana. com/

Kotrba, R. y Bartos, L. (2010). Survey on deer farming in Europe based on questionnaires from Austria, Belgium, Czech Republic, Denmark, France, Germany, Hungary, Italy, Latvia, Lithuania, Netherlands, Norway, Poland, Slovakia, Spain, Sweden, Switzerland and United
Kingdom. FEDFA Meeting, Switzerland, 2010. [En línea]. Disponible en: http:// www.fedfa.org/en/fedfa-org.-data/documents-2767790

La situación de la caza en España (IV): daños, cultivos y caza. Santiago de Compostela. [En línea]. Disponible en: http:// www.fecaza.com/images/stories/PDF/ CONCLUSIONES IV OBSERVATORIO CINEGETICO_RFEC_oct_2010.pdf

Presentación de los datos de consumo alimentario en el hogar y fuera del hogar en España 2012. [En línea]. Disponible en http://www.mapama.gob.es/es/alimentacion/temas/consumo-y-comercializacion-y-distribucion-alimentaria/ Revisado 1300307 PANEL CONSUMO_vFinal_NPD_tcm7-270351.pdf 